\title{
A CONTRAPALAVRA NO GÊNERO CHARGE: UMA ANÁLISE A PARTIR DE BAKHTIN E O CÍRCULO
}

\author{
THE COUNTERWORD IN CHARGEGENRE: AN ANALYSIS FROM BAKHTIN \\ AND THE CIRCLE
}

\author{
Wilder Kleber Fernandes de Santana ${ }^{27}$
}

\begin{abstract}
RESUMO: Uma das premissas do pensamento bakhtiniano é o de que a linguagem consiste em uma atividade essencialmente social e heterogênea, a qual se apresenta perante o pesquisador/orador/expositor/ouvinte de forma multifacetada, em sua dimensão plural, múltipla, densa. Nessa perspectiva, o estudo dos gêneros, como no caso específico da charge, se faz imprescindível para a compreensão desta proposta de análise. A charge é um gênero discursivo cuja constituição - alteritária - se dá numa relação intersubjetiva mediada por múltiplos pontos de vista os quais concretizam os lugares sociais ocupados por esses sujeitos na esfera sócio-ideológica. Objetiva-se identificar, na arquitetônica da materialidade verbo-visual, o posicionamento enunciativo criado pelo(s) sujeito(s) para desconstruir outros discursos, o que se entenderá pela contrapalavra, sobre a manifestação do amor de Deus. Esta reenunciação valorada se estabelece em situações sociocomunicativas orais do uso da língua. Inserindo-se numa perspectiva enunciativo-discursiva da linguagem, no escopo do discurso religioso, este estudo pretende analisar o fenômeno da contrapalavra e das relações axiológicas na arquitetônica da charge "O amor de Deus manifesto", a qual foi publicada no site de notícias "Portal Fiel". Nossa pesquisa norteou-se pela base da Teoria da Enunciação formulada por Bakhtin e o Círculo (2010, 2011, 2012a). De forma complementar, recorremos às pressuposições teóricas desenvolvidas por alguns estudiosos do pensamento bakhtiniano, em terreno brasileiro, como:Brait (2005), Faraco (2009) e Sobral (2009), dentre outros.
\end{abstract}

PALAVRAS-CHAVE: Charge. Contrapalavra. Amor de Deus.

\begin{abstract}
One of the premises of Bakhtin's thought is that language consists anessentially social and heterogeneous activity, which presents it self to the researcher / speaker / exhibitor / listener in a multifaceted way, in its plural, multiple, dense dimension. In this perspective, the study of the genres, as in the specific case of the charge. It becomes essential for the under standing of this proposal of analysis. The charge is a discursive genre that is constituted by otherness, in an intersubjective relationship mediated by multiple points of view which concretize the social places occupied by these subjects in the socio-ideological sphere. The objective of this paper is to identify the enunciative positioning created by the subject (s) to constructor the discourses, which is underst by the counter word, about the manifestation of the love of God. This valued reestablishment is established in oral socio-communicative situations of language use. Inserting it self in an enunciative-discursive perspective of the language, in the scope of there ligious discourse, this study intends to analyze the phenomenon of the counter word and the axiological relations in the architectonic of the charge "The love of God manifesto", which was published in the news site "Portal Fiel". Our research was guided by the basis of theTheory of Enunciation formulated by Bakhtin and the Circle (2010, 2011, 2012a). In a complementary way, we resort to the theoretical presuppositions developed by some scholars of Bakhtinian thought, in Brazilian terrain, such as: Brait (2005), Faraco (2009) and Sobral (2009).
\end{abstract}

KEYWORDS: Charge. Counterword. Love of God.

\section{Um breve percurso da linguagem: da análise formal à dialógica}

A remissão às esferas da religião e ao universo cristão, com suas especificações e símbolos,recorrentes na produção de Bakhtin e o Círculo, vem atraindo a atenção gradativa de estudiosos do pensamento bakhtiniano tanto no cenário nacional quanto no internacional.

Ao observarmos as condições histórico-ideológicas em que Bakhtin situa o contexto das obras de François Rabelais (1494-1553), através de pistas e rastros discursivos

\footnotetext{
${ }^{27}$ Mestre e Bacharel em Teologia pela Faculdade Teológica Nacional (FTN); Mestrando em Linguística pelo Programa de Pós-Graduação em Linguística (Proling) da Universidade Federal da Paraíba (UFPB). Professor Tutor no curso de Pedagogia à Distância da Universidade Federal da Paraíba (UFPB). E-mail: wildersantana92@gmail.com
} 
(VOLOCHINOV, 2017), percebemos a articulação de valores sacros e carnavalescos em diversos eventos culturais populares. Então, na medida em que a literatura renascentista comportava ritos populares entre o sagrado e o profano, "quase todas as festas religiosas possuíam um aspecto cômico popular e público, consagrado também pela tradição" (BAKHTIN, 2010, p. 4). Assim, Bakhtin, considerado um dos principais críticos (da filosofia e da literatura) do século XX, realizou, entre 1920 e 1924, o esboço de uma filosofia do ato ético que dialoga com uma gama de filósofos, desde Aristóteles (sobre a conceituação de ato enquanto potência) a autores dos séculos XVIII a XIX, como Schelling (1775-1854) e Hermann Cohen (1842-1918). Esse reportar-se a outrosconsiste em uma "filosofia do ato (responsável)", título que foi atribuído a um de seus escritos pelo editor russo.

Pouco tempo depois, Medviédev publica "O método formal nos estudos literários ${ }^{28}$ ", obra que apresenta o posicionamento ativo de sua crítica ao formalismo europeu, especificamente o russo. Sua crítica alerta sobre a importância de se trabalhar com a arte em sua totalidade, e não apenas através da arte como procedimento (Chklovsky). Portanto, seria preciso ir contra as tendências formalistas procedimentais, em que a ciência das ideologias estava desvinculada dos seus campos particulares, como a religião, a ética, a literatura, a moral etc.

Em contrapartida à perspectiva formalista, Volochínov (1930) postula que três aspectos concretizam a dimensão extraverbal do enunciado: o espaço e o tempo do evento, o objeto ou o tema do enunciado (aquilo de que se fala) e a posição dos interlocutores diante do fato - a "avaliação". A situação consiste no modo como esses três aspectos dialogam. Assim, quaisquer enunciados, para que sejam compreendidos, devem ser considerados na interrelação desses três elementos, no intuito de produzir sentidos. Nas palavras do autor,

Sem o liame que a situação cria entre os locutores, sem uma proximidade do evento que lhes é comum, e sem a posição de cada um face a este evento, as palavras pronunciadas por um seriam ininteligíveis para o outro, destituídas de sentidos, desprezáveis. É unicamente porque existe alguma coisa de "subentendida" que a comunicação e a interação verbal se tornam possíveis. (VOLOCHINOV, 1930, p. 10, destaque do autor).

Em mesmo direcionamento, as produções de Bakhtin e Medviédev, na proporção que tecem as bases de uma filosofia da vida (Lebensphilosophie ${ }^{29}$ ), posicionam-se criticamente à "filosofia da cultura", que tem como um dos principais representantes Henri Bergson (18591941), com o idealismo alemão. É em meio à crise da "Filosofia da cultura idealista e do positivismo nas ciências humanas" (MEDVIÉDEV, 1928 [2016], p. 45) que os estudiosos russos propõem novas maneiras de análise e observação da linguagem, levando-se em conta os meios de produção, tanto na vida quanto na arte.

Assim, nossa análise incidiu sobre as relações axiológicas na charge "O amor de Deus manifesto", em sua densidade dialógica, que adquire concretude e expansão analítica em múltiplos campos do saber, tais como o histórico, o ideológico e o religioso. Reconhece-se que há em Bakhtin e o círculo múltiplos traços enunciativos das temáticas "responsividade e axiologia". Além de diversas contribuições para o debate sobre a dimensão ético-cognitiva, encontramos, nas produções dos russos, novas propostas para a construção do enunciado, a exemplo das esferas

\footnotetext{
${ }^{28}$ De acordo com Brait (2016, p.13), na Apresentação do livro de Medviédev, "Trata-se de um estudo publicado em 1928... notabilizado pelo diálogo polêmico com a importante vertente de estudos literários: o formalismo russo".

${ }^{29}$ A filosofia da vida é considerada não-transcendental, uma vez que se centra no mundo concreto e não em princípios alheios a ela e "não imanente", uma vez que se centra no agir dos sujeitos, prestando ênfase ao processo da ação, sem deixar de levar em conta os seus resultados. (cf. Sobral, 2005a).
} 
estética e religiosa. Para o nosso propósito específico, delimitaremos como esta proposta analítica se materializa no gênero discursivo charge.

Nossa pesquisa norteou-se pela base da Teoria da Enunciação formulada por Bakhtin e o Círculo $(2010,2011,2012 \mathrm{a})$ e sobre os conceitos de Contrapalavra, relações responsivas e axiológicas. De forma complementar, recorremos às pressuposições teóricas desenvolvidas por alguns interlocutores bakhtinianos, em terreno brasileiro, como:Fiorin (2003), Brait (2005), Faraco (2009) e Sobral (2009), dentre outros.

Quanto às nossas categorias de análise, tanto a contrapalavraquanto a axiologia consistem em termos utilizados nas produções filosóficas e literárias de Bakhtin, assim como pelos membrosdo círculo. As primeiras vezes em que Bakhtin as utiliza é na composição "Para uma filosofia do Ato", esboço sobre o Ato e os atos humanos [em processo] e sobre sua linguagem e seus meios de diálogo vivo, o qual classifica como necessário à condição concreta da vida. Para Bakhtin, a língua deve ser

[...] ideologicamente preenchida, a língua enquanto cosmovisão e até como uma opinião concreta que assegura um maximum de compreensão mútua em todos os campos da vida ideológica. Por isso a língua nunca exprime as forças da unificação verboideológica concreta e da centralização que ocorre numa relação indissolúvel com os processos de centralização sociopolítica e cultural. (BAKHTIN, 2015 , p. 40 - grifo do autor)

Assim, os discursos que se encontram atravessados por vozes outras não têm sentido único, mas seus sentidos múltiplos se concretizam através da axiologia, ou a capacidade que os enunciados têm de se interligarem, através de um processo de valoração. "Em cada momento concreto da formação discursiva, os enunciados são estetificados em camadas socioideológicas, ou seja, manifestam-se através da história e da memória culturais (processo de estetificação)" (SANTANA, 2017, p. 237). É essencial, na proposta de Bakhtin e o Círculo, que sejam considerados os gêneros discursivos em sua arquitetônica, ou seja, em sua completude, tanto em suas estruturas internas quanto em seu acabamento e no extraverbal.

Para Bakhtin, a compreensão da contrapalavra consiste em réplicas, por parte dos interlocutores, os quais constroem discursos que vão de encontro a outras produções enunciativas, sejam através de concordância, discordância, negação, recusa etc. Bakhtin se utiliza desta categoria para mostrar que, no momento em que os sujeitos falam, produzem enunciados que respondem ao seu interlocutor. Enquanto ouvimos, também falamos. Desse modo, ouvir e falar são movimentos de uma mesma atividade discursiva.

As réplicas produzidas, dentro de um enunciado, são formuladas a partir da relação do sujeito com a alteridade, ou seja, a produção dacontrapalavrase concretiza em relação às palavras de outrem. Esta categoria é fundamental para a compreensão ativa e responsiva do enunciado. É importante ressaltar também que a contrapalavra, assim como a palavra, está estritamente associada ao tema da interação,em que os sentidos são construídos na interação com outro, e à entonação escolhida para a enunciação.Não há possibilidade de compreensão da palavra alheia por osmose nem por coerção, mas sim através do dialogismo em produção de múltiplos sentidos.

\section{Em se tratando de Gêneros}

Brait (2005/2006) reflete sobre o fato de que, no Brasil, o conceito de gênero tem adquirido ampla visibilidade tanto em documentos oficiais de ensino/aprendizagem quanto e em materiais didáticos, e isso sugere, em relação aos que o mobilizam didática e/ou 
academicamente, que sejam responsáveis por considerar as suas dimensões sócio-históricas e de produção discursiva.

Volochinov (2017, p. 153) postula, sobre a contrapalavra, que um enunciado é atravessado "pela ressonância longínqua e quase inaudível da alternância dos sujeitos falantes e pelos matizes ideológicos, pelas fronteiras extremamente tênues entre os enunciados e totalmente permeáveis à expressividade do autor" (VOLOCHINOV, 2017, p. 153). A partir desse conjunto de proposições em torno do enunciado, compreendemos que a alternância dos sujeitos é parte constitutivamente integrante no processo de composição da interação, da ordem daquilo que integra a construção do diálogo. Essas remissões interativas se constituem pelo desenvolvimento da comunicação da sociedade, através de particularidades próprias de determinada comunicação.

Em mesma linha analítica de produção, Bakhtin (2006) desenvolve seu estudo sobre os gêneros do discurso, no intuito de compreender a variedade de formas semiestabilizadas de comunicação. Para o filósofo russo $(2006$, p. 280), a riqueza e a variedade dos gêneros são infinitas, pois, explica o autor, a variedade virtual da atividade humana é inesgotável, e cada esfera dessa atividade "comporta um repertório de gêneros do discurso que vai diferenciandose e ampliando-se à medida que a própria esfera se desenvolve e fica mais complexa". Ele define gêneros do discurso como "tipos relativamente estáveis de enunciados" (BAKHTIN, 2006, p. 280 - grifos do autor), elaborados pelas esferas de utilização da língua, e desenvolve a problemática dos gêneros, defendendo que o estudo da natureza do enunciado e da diversidade dos gêneros de enunciados nas diferentes esferas da atividade humana tem importância capital para todas as áreas da linguística e da filologia (SANTANA, 2017).

Volochinov (2017) afirma que o enunciado, em seu percurso de existência e circulação, de maneira significativa num determinado momento social e histórico, não pode deixar de tocar os milhares fios dialógicos existentes, tecidos esses que perpassam pela consciência ideológica em torno de um dado objeto da enunciação. Esse, portanto, não pode deixar de ser participante ativo do diálogo social.

Por essa perspectiva, podemos afirmar que o gênero charge se constitui de uma relativa estabilidade do enunciado, constituído pela clara relação entre o verbal e o não verbal, resultando em um discurso verbo-visual. Assim, afirma Francelino (2011, p. 05) que tais características desse gênero abrangem sua estrutura enunciativa pela veiculação de "uma posição ideológica, uma visão de mundo, um ponto de vista acerca de um objeto de discurso".

\subsection{A contrapalavra no gênero charge}

A palavra chargeé de origem francesa, e possui sentido de carga, peso, exagero. Quanto aos estudos de gênero, a charge consiste em um tipo de enunciado que, propositadamente, exagera nos elementos e detalhes do caráter de alguém, ou de algo, para torná-lo cômico.Enquanto gênero discursivo, esta será analisada não apenas sob seus aspectos morfossintáticos, mas sobretudo os aspectos axiológicos presentes em sua construção dialógica. Isso significa que a contrapalavrae a axiologia consistemna remissão valorada, em que se recupera(m) o(s) discurso(s) outro(s) que se faz(em) presente(s) neste discurso, que $\mathrm{o}(\mathrm{s}) \operatorname{atravessa}(\mathrm{m})$, aqui e agora.

A responsividade consiste no agir ético em que os sujeitos da enunciaçãose responsabilizam pelo que proferem, permitindo-se seremclarosao(s) outro(s), e este(s) se insere $(\mathrm{m})$ na história enquanto agente(s) racionalmente ativo(s). Assim, a concretude da compreensão responsiva-ativa, em uma charge, está no dialogismo, quando o leitor é capaz de compreender o que perpassa aquela construção de vozes presentes, vezes situadas historicamente, revestidas por forças centrífugas e centrípetas que lhe dão múltiplos 
sentidos.Portanto, a responsividade indica que cada elemento concludente se correlaciona com outros elementos de outras obras-enunciados (BAKHTIN, 2006) dialogicamente: "um ponto de vista a outro ponto de vista, uma avaliação a outra avaliação, um acento a outro acento (e não como dois fenômenos linguísticos abstratos)" (BAKHTIN, 2015, p. 99).

Neste mesmo horizonte, a axiologia diz respeito às atribuições de valor(es) presentes na charge a partir dos diálogos provocados entre autor e personagem. Conforme Santana (2017, p. 240),

A valoração é um elemento importante na obra, em que o autor justapõe responsivamente os enunciados (e todos os outros elementos) à história e à memória ideológica sociais. Esse plano, chamado de axiologicamente valorativo, se faz de modo responsavelmente racional, ou seja, é o ponto nevrálgico em que a obra mantém contato pleno com outras vozes que a atravessam, e aí reside seu valor interdiscursivo(SANTANA, 2017, p. 240).

Este "valorar" não permanece em níveis literários, mas é trazido para a esfera ética, em que os seres humanos, na medida em que produzem e proliferam seus discursos, o fazem de modo responsivamente axiológico, compreendendo que o outro com o qual dialoga é quem o constitui.Nas palavras de Santana (2017), ovalor axiológico que um autor-contemplador ${ }^{30}$ pode atribuir a uma obra, ao lê-la, concluí-la, ao delimitá-la com seus tons emotivos-volitivos, consiste em transferir a esse objeto os diálogos existentes em seu interior, ou seja, o estabelecimento de vínculos desta com outras obras/vozes/valorações. Os sujeitos do discurso, então, não devem vivenciar suas enunciações para si mesmos, mas sempre pensando que o vivenciamento de uma postura axiológica consiste na presença constitutiva do outro em mim (outros enunciados que atravessam os discursos os quais profiro).

$\mathrm{A}(\mathrm{s})$ crítica(s) presente(s) na charge torna(m)-se nítida(s) ao leitor quando são levados em conta fatores dialógicos, assim como os entornos que engendram o enunciado, em sua arquitetônica. A vida e a arte estão inter-relacionadas por fronteiras de expressividade, e desse modo alcançam-se os sentidos múltiplos que estão representados pelo verbo-visual. Desse modo também se constituem as vozes como potencialmenteativasa determinado constructo social e ideológico.

No referente ao gênero em questão, ainda que o conteúdo temáticocomporteassuntosplurais e multissêmicos, é notória a recorrência a assuntos de grandes áreas, como política, educação e religião, sempre em dimensão sócio-histórica, em que geralmente está incluída uma crítica social através do humor.

Apesar de a charge se caracterizar por usar uma linguagem mista (verbal e extraverbal), com relação ao estilo composicional, nem sempre percebemos a presença de elementos verbais. A partir das proposições de Bakhtin (2006, p. 282), podemos enquadrá-lo dentro dos gêneros secundários ou mais complexos, pois aparecem em circunstâncias de uma comunicação cultural mais complexa e relativamente mais evoluída, especialmente a escrita. Esta modalidade enunciativo-discursiva utiliza-se da ironia ou de situações absurdas, e geralmente será preciso de um raciocínio mais elaborado para compreendê-la. Porém, muitas vezes almeja-se transmitir uma contrapalavra, no sentido de retomar uma perspectiva ideológica e confrontá-la, e reenunciá-la.

30 A categoria bakhtiniana "autor-contemplador" se refere ao autor que constrói os sentidos presentes em determinado/a objeto/obra a partir de seu(s) ponto(s) de vista, após o primeiro estado: o da contemplação. Após contemplar o objeto que se coloca à sua frente, os sentidos vão sendo construídos a partir da inter-relação entre as partes e o todo, constituintes da obra. 
Enquanto material de circulação social, a charge exibe recortes de temas relacionados ao meio político-ideológico-social utilizando-se, além de elementos morfossintáticos, frases de efeito e ironia, de recursos imagéticos, como caricaturas, imagens metafóricas e símbolos. As partes integrantes do enunciado podem veicular discursos clássicos, como no caso do amor que advém de um ícone do Cristianismo.Noque respeita à construção composicional, a charge é curta, e retrata discussões recentes ou não, cujas assinaturas instauram, para o leitor, rastros e pistas para que este acesse informações interdiscursivas para compreendê-la.

Portanto, é assim que se expõe o corpus de nossa análise: a charge "O amor de Deus manifesto", em sua densidade arquitetônica, em que sua compreensão responsivo-ativa se concretiza na ressonância de outras vozes - orquestração plurivocal. É através do princípio de transgrediência, de retomadas históricas, que é conferida vida a qualquer enunciado, este é (en)formado, e agenciado pelo caráter excedente do acontecimento ideológico.

\section{A Charge em análise: uma proposta de compreensão responsiva-ativa}

\section{Imagem 1: $O$ amor de Deus manifesto}

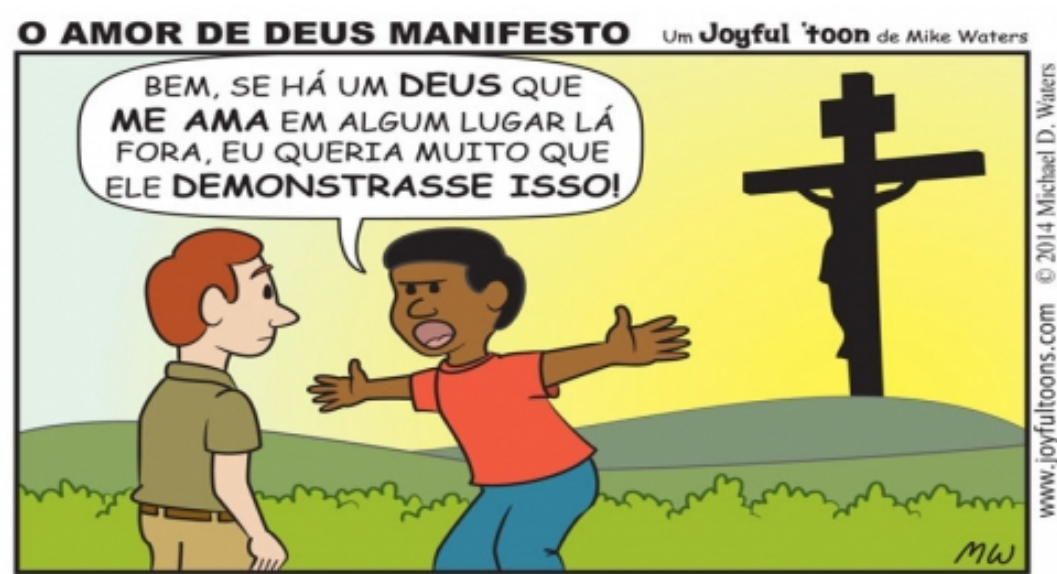

Mas Deus demonstra seu amor por nós: Cristo morreu em nosso favor quando ainda éramos pecadores. - ROMANOS 5:8 NVI

Fonte: http://www.portalfiel.com.br/uploads/charge/charge-gospel-o-amor-de-deus-manifesto-35-13b127793d8c2c42cf9b58acd114ff33.jpg

Um dos sentidos plurais que podem ser evidenciados nesta materialidade enunciativa exige de seu leitor que possua conhecimento da realidadesócio-históricado Cristianismo e dos motivos pelos quais houve o acontecimento da crucificação de Jesus Cristo, ícone máximo desta perspectiva religiosa, além de alguns posicionamentos religiosos que se configuram neste cenário. Desse modo, é necessário se remeter especificamente às condições ideológicas em que o material foi construído.

No processo decriaçãode "O amor de Deus manifesto" (2014), Mike Watersnão só cria, mas relaciona os traços dialéticos entre a parte e o todo: os sujeitos, a partir do seu dizer/fazer, são interseccionados pela simultaneidade de ser/Ser na linguagem, e é nesse instante que os sujeitos se constituem: um através do outro, no diálogo. Quanto à paisagem, a unidade arquitetônica é condensada pela multiplicidade de suas partes, seja através do jogo de cores ou os esquemas discursivos, pois os sujeitos, criadores do movimento semântico, exploramas camadas estético-ético-cognitivas, num processo de comunicação verbi-vocovisual (FERRARA, 1978). Nesse sentido, além da configuração da (dia)lógica interna 
modulada nas enunciações, faz-se imprescindível observar as expressões de cada personagem, assim como o acabamento dos elementos componentes.

$\mathrm{Na}$ charge há duas personagens que dialogam, e toda a arena espacial, assim como os elementos constitutivos, demonstram que estão em um campo, ao ar livre. Do lado direito temos a figura de um rapaz com expressão de raiva, revolta e ao mesmo tempo incompreensão acerca de um discurso bastante comum no Cristianismo: o amor de Deus.Do lado esquerdo, há outro rapaz com uma expressão de surpresa, mostra-se pasmado, provavelmente por ter um conhecimento transgrediente acerca do assunto abordado pelo seu interlocutor. Em termos cenográficos (MAINGUENEAU, 2012), percebemos que o evento chargístico ocorre ao entardecer, pois o jogo de cores revela uma cor amarelo-escuro no canto direito.

O sujeito da enunciação profere as seguintes palavras: "Bem, se há um Deus que me ama em algum lugar lá fora, eu queria muito que ele demonstrasse isso!" (grifos do autor). Por mais que só tenhamos acesso a essas palavras e não a outras anteriores, supõe-se que se trate de uma réplica, ou seja, o fenômeno da contrapalavra em relação a um acontecimento histórico e religioso:a crucificação de Jesus Cristo e sua simbolização, ou seja, seu auto oferecimento pela humanidade. A Bíblia Cristã, livro adotado pelos cristãos como sendo uma compilação de escrituras sagradas, apresenta o fato de Deus ter amado o mundo "de tal maneira que deu seu filho unigênito para que todo aquele que nele crer não pereça, mas tenha vida eterna" (Jo 3.16).

A enunciação do sujeito, logo de início, revela dúvida: a expressão "se há um Deus que me ama..."indica que o locutor não tem certeza se esse "Deus" realmente o ama ou não, na medida em que expressa um tom emotivo-volitivo de incredulidade, e assim é demarcado o posicionamento axiológico desse sujeito nessa enunciação: o de cético, alguém que só acredita naquilo que vê. De igual modo, as palavras “...em algum lugar lá fora” indicam o desconhecimento por parte do sujeito enunciativo sobre um lugar metafísico ou espiritual, de morada de Deus, o que também é confirmado pelo livro adotado pelos cristãos.

Por fim, a expressão "eu queria muito que ele demonstrasse isso"externaliza muito mais que um querer. Demonstra entonação avaliativarevolta, pelo fato de o sujeito não ter passado pela experiência de Deus ter demonstrado este amor por ele. Porém, neste momento, temos acesso a outros dados, que não estão apenas no nível linguístico (verbal), mas no plano extraverbal (imagético).

A construção arquitetônica da charge nos faz perceber que o demonstrativo "isso" não faz referência apenas ao amor, presente no enunciado, está ligado diretamente ao gesto feito pelo sujeito falante, que estende seus braços, e alonga-os em forma de cruz. É então que, propositadamente, o autor Mike Waters projeta, a poucos metros de distância do sujeito enunciativo, especificamente atrás deste, uma cruz, contendo um homem, e este crucificado, com os braços projetados da mesma forma como o falante demonstra: estendidos, alongados para direita e esquerda. Tanto o homem que está erguido na cruz quanto a própria cruz estão revestidos de cor preta, o que remete diretamente ao tom emotivo-volitivo de zombaria, revolta, rejeição ao discurso religioso cristão, por parte do sujeito falante acerca do acontecimento histórico da crucificação de Jesus Cristo, ou pelo menos dos seus sentidos simbólicos.

Segundo Sobral (2009, p.84), todo ato traz um tom avaliativo pelo qual o sujeito se responsabiliza, envolvendo um conteúdo e um processo, "que adquirem sentido ao ser unidos pela entoação avaliativa em sua relação com a responsividade ativa", ou seja, o interlocutor não é apenas um decodificador do enunciado alheio, mas um co-produtor de sentidos.

Aqui vemos explicitamente o fenômeno concreto da contrapalavra, pois o todo enunciativo do sujeito falante é construído em uma perspectiva contrária a outros ensinamentos que foram fortalecidos dentro da doutrina cristã e da história do Cristianismo. 
Diante disso, há algumas palavras que estão logo abaixo das margens do material da charge, mas que fazem parte da construção arquitetônica, ou seja, estãoalém de seus limites estruturais. Provavelmente essas palavras representam o pensamento do sujeito da esquerda, de pele branca, que aparenta ser detentor do conhecimento bíblico e histórico acerca do acontecimento da crucificação de Jesus Cristo por um propósito de Deus em ter sacrificado seu próprio filho por amor à humanidade.Essas palavras expressam tanto o pensamento do sujeito que está do lado esquerdo quanto o que o apóstolo Paulo, um dos principais expoentes e defensores da doutrina cristã no primeiro século depois de Cristo, escreveu aos romanos: Mas Deus demonstra o seu amor por nós: "Cristo morreu em nosso favor quando ainda éramos pecadores" ( Rm 5.8).

Então, temos acesso a mais réplicas: o pensamento deste último sujeito simboliza sua contrapalavra, ainda que não tenha sido expressada enunciativamente. $\mathrm{O}$ fato de nós, leitores, termos acesso a seus pensamentos corrobora o fato de que há, além dos limites das palavras ditas, sentidos outros que podem ser construídos, a partir do instante em que correlacionamos informações mediante o estabelecimento de relações dialógicas.Em outras palavras, tanto a contrapalavra quanto as relações axiológicas e valorativas são demonstradas na arquitetônica da charge, uma vez que o todo do enunciado é explorado ao máximo em remissão a símbolos cristãos e palavras que reacentuam uma arena de vozes solidificada ideologicamente.

Podemos, portanto, dizer que as personagens da charge, ao recorrerem (enunciativamente ou não) a outras vozes, no elo da cadeia enunciativa, assumem sua própria assinatura, conferindo um horizonte axiológico ao que dizem, já que "as seleções e escolhas são, primordialmente, tomadas de posições axiológicas frente à realidade linguística, incluindo o vasto universo de vozes sociais" (FARACO, 2009). Os sujeitos, ao reacentuarem temáticas já solidificadas por uma coletividade, o fazem "em seus próprios termos", pelos quais tem de responsabilizar-se (SOBRAL, 2009, p.232).

\section{Considerações Finais}

Para Bakhtin, toda compreensão ativa exige uma atitude responsiva. O fenômeno da contrapalavra requer dos sujeitos da enunciação que possuam conhecimentos prévios para que possam teratitudescríticasresponsivas diante de outros enunciados, posicionando-se contra. A compreensão da crítica presente na charge, seja de temática política e/oureligiosa, desperta um olhar para a realidade na qual o sujeito está inserido.

A fim de averiguarmos o fenômeno da contrapalavrana charge "O amor de Deus manifesto" (2014), do autor Mike Waters, buscamos subsídios nas reflexões teóricas de Bakhtin e o círculo, a fim de identificamos as marcas enunciativas responsáveis pela análise dialógica de um discurso crítico sobre um fenômeno simbólico e acontecimento histórico do Cristianismo. Nesse horizonte, o fenômeno da contrapalavra, conforme Volochinov (2017) apresenta, não significa apenas se posicionar contra determinados assuntos, mas reenunciálos, retomá-los sob novos pontos de vista, prestar-lhes novo acabamento.

Defende-se neste trabalho que todo enunciado construído racionalmente é responsivo, porque evoca, no elo da cadeia discursiva, réplicas (contrapalavra ou não) a partir de uma dada posição social. Percebe-se que nesta construção arquitetônica são importantes para a compreensão o tom avaliativo, as assinaturas linguístico-discursivas, mas também a dimensão extraverbal do enunciado, como os símbolos presentes na charge e a remissão a outras vozes. Há, portanto, na materialidade verbo-visual, a ressonância de outras vozes que não corroboram o acontecimento histórico da crucificação de Jesus Cristo e de seus sentidos atribuídos pelo Cristianismo e seus seguidores.

Com isso, temos acesso a uma construção que traz duas posições axiológicas sobre o tema do amor de Deus e da crucificação de Cristo: o sujeito da esquerda mantém seu saber solidificado 
ideologicamente, enquanto o sujeito que se encontra na dimensão direita da charge demonstra ceticismo. Nesse sentido, o saber sobre um acontecimento históricoé essencial na orquestração de vozes sociais que se constituem para a compreensão responsivo-ativa tanto dos sujeitos que dialogam quanto do(s) leitor(es) do(s) enunciado(s).

\section{REFERÊNCIAS}

BAKHTIN, Mikhail M. Para uma filosofia do ato responsável. $2^{\mathrm{a}}$. ed. Pedro \& João Editores. São Carlos, 2012.

. Teoria do romance I: a estilística. Trad./prefácio Paulo Bezerra. São Paulo: Contexto, 2015.

. Estética da Criação Verbal.[tradução feita a partir do russo; tradução Paulo Bezerra]. 5a.ed. São Paulo: Martins Fontes, 2006.

BÍBLIA SAGRADA (Bíblia de promessas) Trad. João Ferreira de Almeida. Co-edição (JUERP) Imprensa Bíblica Brasileira King’s Cross publicações. Revisão do Estudo das promessas - Luiz Saião. Edição Revista e Corrigida. 15a edição, 2010.

BRAIT, Beth. Bakhtin: conceitos-chave. São Paulo: Contexto, 2005.

FARACO, Carlos Alberto. Linguagem \& diálogo: as idéias linguísticas do círculo de Bakhtin. São Paulo: Parábola, 2009.

FERRARA,Lucrecia D'Alessio. O texto estranho. São Paulo, Ed. Perspectiva, 1978. FRANCELINO, Pedro Farias. Enunciação, dialogismo e autoria em enunciados midiáticos verbo-visuais. Revista MOARA n.36, p.104-114, Estudos Linguísticos, jul.-dez, 2011. MAINGUENEAU, Dominique. Discurso Literário. Tradutor: Adail Sobral. $2^{\mathrm{a}}$ edição. São Paulo: Contexto, 2012.

MEDVIÉDEV, PávelNikoláievitch. O Método Formal nosestudosliterários: introdução a umapoéticasociológica. Tradutoras: Sheila Camargo Grillo e EkaterinaVólkovaAmérico $-1^{\text {a }}$ ed. São Paulo: Contexto, 2016.

SANTANA, Wilder Kleber Fernandes de.Heterodiscursividade e Axiologia no primeiro capítulo do Cântico Dos Cânticos. In: SINALP - Simpósio Nacional de Literatura Popular, 2017, Joao Pessoa. Cultura Popular e Cosmopolitismo - Simpósio Nacional de Literatura Popular. Joao Pessoa: Midia Editora, 2016. v. 1. p. 6-247.

SOBRAL, Adail. Do dialogismo ao gênero: as bases do pensamento do círculo de Bakhtin. Campinas: Mercado de Letras, 2009.

VOLOCHÍNOV, V. N. Estrutura do enunciado. Tradução de Ana Vaz, para fins didáticos. 1930, com base na tradução francesa de Tzevan Todorov ("La structure de l'énoncé, 1930). In: TODOROV, T. Mikhail Bakhtine: leprincipedialogique. Paris: Seuil, 2005. p. 287-316. . Marxismo e filosofia da linguagem - Problemas fundamentais do método sociológico na ciência da linguagem.Tradução de Sheila Grillo e EkaterinaVólkova Américo - Ensaio introdutório de Sheila Grillo. 1 ${ }^{\mathrm{a}}$ ed. São Paulo: Editora 34, 2017.

Recebido em 10/08/2017

Aceito em 20/12/2017 